\title{
Melatonin Improves Drought Resistance in Maize Seedlings by Enhancing the Antioxidant System and Regulating Abscisic Acid Metabolism to Maintain Stomatal Opening Under PEG-Induced Drought
}

\author{
Zhuo $\mathrm{Li}^{1} \cdot$ Xiaoyu Su${ }^{1} \cdot$ Yulu Chen ${ }^{1} \cdot$ Xiaocong Fan ${ }^{1} \cdot$ Lingzhi He $^{1} \cdot$ Jiameng Guo ${ }^{1,2} \cdot$ Yongchao Wang ${ }^{1,2}$. \\ Qinghua Yang ${ }^{1,2}$
}

Received: 19 August 2020 / Revised: 4 January 2021 / Accepted: 5 January 2021 / Published online: 29 January 2021

(C) The Author(s) 2021

\begin{abstract}
Maize (Zea mays L.) is highly sensitive to drought stress, resulting in large losses in yield; therefore, strategies aimed at enhancing drought tolerance are essential. Melatonin improves stress tolerance in plants; however, its mechanism in maize seedlings under drought stress remains unknown. Therefore, we investigated the effects of foliar-sprayed melatonin (100 umol $\mathrm{L}^{-1}$ ) on the antioxidant system, photosynthetic gas exchange parameters, stomatal behavior, endogenous melatonin and abscisic acid (ABA)-related gene expression in maize seedling leaves under 20\% polyethylene glycol (PEG)-induced drought stress. PEG treatment resulted in oxidative stress and stomatal closure, resulting in chlorophyll degradation and inhibition of photosynthesis; thereby, reducing seedling biomass. Melatonin pretreatment significantly improved the relative water content, photosynthetic gas exchange parameters and stomatal behavior; thereby, maintaining chlorophyll contents and photosynthesis. Melatonin also stimulated the antioxidant system, enhancing the clearance of reactive-oxygen species, preventing severe damage under PEG-induced drought. Pre-treatment also increased endogenous melatonin and inhibited up-regulation of NCED1, an ABA synthesis-related gene, as well as selectively up-regulating ABA catabolic genes $A B A 80 x 1$ and $A B A 80 x 3$, reducing $\mathrm{ABA}$ accumulation and inducing stomatal reopening. Overall, these findings suggest that melatonin pre-treatment alleviated the inhibitory effects of drought stress on photosynthesis, enhancing tolerance in maize seedlings.
\end{abstract}

Keywords Maize $\cdot$ Drought stress $\cdot$ Melatonin $\cdot$ Photosynthesis $\cdot$ Abscisic acid $\cdot$ Stomata

\section{Introduction}

As sessile organisms, plants are inevitably exposed to various environmental stresses (Gururani et al. 2015), of which drought is one of the most common, occurring annually in many regions around the world and subsequently inhibiting

Zhuo Li and Xiaoyu Su have contributed equally to this work.

Qinghua Yang

yangqh2010@163.com

1 Present Address: College of Agronomy, Henan Agricultural University, \#15 Longzi Lake University District, Zhengdong New District, Zhengzhou 450046, Henan, People's Republic of China

2 National Key Laboratory of Wheat and Maize Crop Science, Zhengzhou 450046, People's Republic of China plant growth and development (Avramova et al. 2015). When plants experience drought stress, transpiration rates decrease and active transport is impaired; thereby, affecting nutrient transport from the roots to the shoots and seriously reducing overall biomass (Griffiths and Parry 2002). Drought stress also causes a significant decrease in the relative water content (RWC) of the leaves, directly inducing toxicity in plant cells (Meher et al. 2018).

Stomata regulate the flow of gases and water in and out of plants, which plays an important role in overall survival (Peterson et al. 2010). In order to reduce water losses under drought stress, the stomata close as a result of changes in the turgidity of guard cells relative to epidermal cells; thereby, reducing the transpiration rate and limiting the diffusion of $\mathrm{CO}_{2}$ into intercellular spaces, ultimately inhibiting photosynthesis (Cornic 2000). Meanwhile, drought also triggers other factors that have an inhibitory effect on photosynthesis 
(Chaves and Oliveira 2004). The antioxidant defense system removes reactive-oxygen species (ROS) in response to the external environment and aging, resulting in a dynamic balance. However, redox imbalance due to drought causes over production and accumulation of ROS, which induce membrane lipid peroxidation and impair membrane function, ultimately leading to chlorophyll degradation and loss of photosynthetic activity (Ippolito et al. 2011; Li et al. 2011; Anjum et al. 2017). In this case, plants activate their antioxidant system to cope with ROS-induced oxidative stress, employing enzymatic [superoxide dismutase [SOD), peroxidase (POD) and catalase (CAT)] and non-enzymatic antioxidants (glutathione (GSH)] (Anjum et al. 2011; Ashraf et al. 2015). Abscisic acid (ABA) is a hormone that regulates plant growth and development as well as the responses to stress (Kushiro et al. 2004). Drought stress triggers ABA production via 9-cis-epoxycarotenoid dioxigenase (NCED), a key enzyme in the ABA biosynthesis pathway. Meanwhile, the main pathway of ABA catabolism is mediated by cytochrome $\mathrm{P} 450$ monooxygenase $\mathrm{ABA}$ 8'-hydroxylase (ABA8ox), also known as CYP707A (Qin and Zeevaart 1999; Saito et al. 2004; Nambara and Marionpoll 2005). The accumulation of ABA in plant cells is closely associated with ROS production, with drought stress stimulating the activation of $\mathrm{Ca}^{2+}$ channels in the plasma membrane, inducing ABA accumulation to regulate stomatal closure (Hu et al. 2008; Liu et al. 2010; Zhou et al. 2014).

Melatonin ( $\mathrm{N}$-acetyl-5-methoxytryptamine) was first discovered in the bovine pineal gland (Lerner et al. 1958) and has since been found in a variety of plant species, gaining widespread attention among biologists (Paredes et al. 2009; Tan et al. 2012; Arnao and Hernandezruiz 2014). Participation in various physiological processes, such as seed germination (Tiryaki and Keles 2012), root growth (Zhang et al. 2013) and leaf senescence has so far been demonstrated (Wang et al. 2014). Melatonin has also been shown to improve tolerance to drought, salinity and chilling stress (Park 2011; Janas and Posmyk 2013; Wei et al. 2015), as well as acting directly as an effective antioxidant, enhancing plant resistance by decreasing ROS accumulation (Arnao and Hernandezruiz 2015; Liu et al. 2015). In maize seedlings, melatonin increased drought tolerance by alleviating drought-induced photosynthetic inhibition and oxidative damage (Ye et al. 2016), while in hickory it preserved functionality of photosynthetic apparatus by stimulating antioxidant activity and expression levels of antioxidant enzymes under drought stress (Wang et al. 2019a). Wang et al. (2013) also revealed that exogenous application of melatonin delayed senescence of apple leaves under longterm drought stress, while Li et al. (2015) showed that melatonin-maintained drought tolerance in apple plants by regulating ABA metabolism and stomatal behavior. Melatonin has also been shown to prevent chlorophyll degradation by down-regulating chlorophyll-degrading enzymes in tomato leaves (Wang et al. 2019b), while application effectively reduced drought stress in wine grapes (Meng et al. 2014). Meanwhile, in a recent study, melatonin delayed MeJAinduced senescence in tomato leaves, while pre-soaking of wheat seeds with melatonin improved yield by delaying leaf senescence and promoting root development (Ye et al. 2020).

Maize is one of the most important cereals in the world as well as being extremely sensitive to drought stress. Drought stress during maize growth can therefore lead to significant reductions in yield (Ziyomo and Bernardo 2013; Lobell et al. 2014), highlighting the need for scientific research aimed at improving drought tolerance. Studies suggest that melatonin could effectively improve drought tolerance in crops; however, few studies have targeted important crops such as maize. As a result, not much is known about the mechanism of melatonin in maize seedlings. Polyethylene glycol (PEG) is often used to simulate drought stress in experimental studies since PEG molecules with a molecular weight of more than 3000 are not absorbed by plant cells, preventing toxic side effects (Emmerich and Hardegree 1990). In this study, maize seedling leaves were pre-treated with melatonin before being subjected to PEG-induced drought stress. The effects on morphological characteristics, antioxidant enzyme activities, photosynthetic parameters, stomatal behavior and expression levels of key enzyme genes involved in the ABA metabolic pathway were then examined. The protective mechanism of melatonin on maize seedlings under drought stress was subsequently discussed from a physiological and metabolic perspective.

\section{Results}

\section{Melatonin Improved the Biomass of Maize Seedlings Under Drought Stress}

PEG-induced drought had severe toxic effects on the phenotype of the maize seedling leaves; however, pre-treatment with melatonin alleviated this damage, with relatively significant changes on day 3 and 4 (Fig. 1a). When compared with the control (CK), PEG treatment (D) caused a significant reduction in plant height, leaf length and width, and the dry weight of the maize seedlings. Meanwhile, melatonin pretreatment $(\mathrm{MT}+\mathrm{D})$ effectively alleviated the PEG-induced negative impact on all traits (Table 1). No significant differences were observed between $\mathrm{CK}$ and melatonin pre-treatment alone (MT); however, compared with D treatment, the height of the seedlings increased by $8.93,7.29,9.93$ and $10.42 \%$ under MT $+\mathrm{D}$ treatment on day $1,2,3$ and 4 , respectively. Moreover, leaf length increased by $5.33,8.24,10.06$ and $12.80 \%$, leaf width increased by $10.24,11.38,15.38$ 
(a)

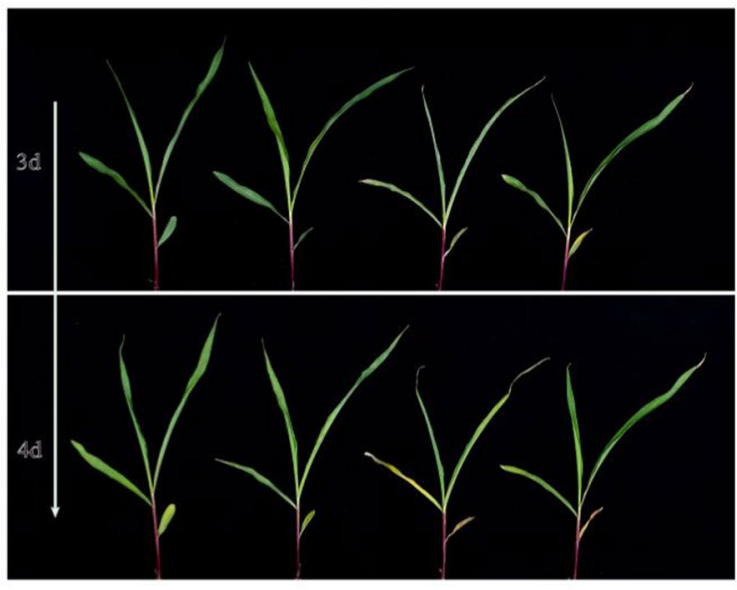

CK

MT

(b)

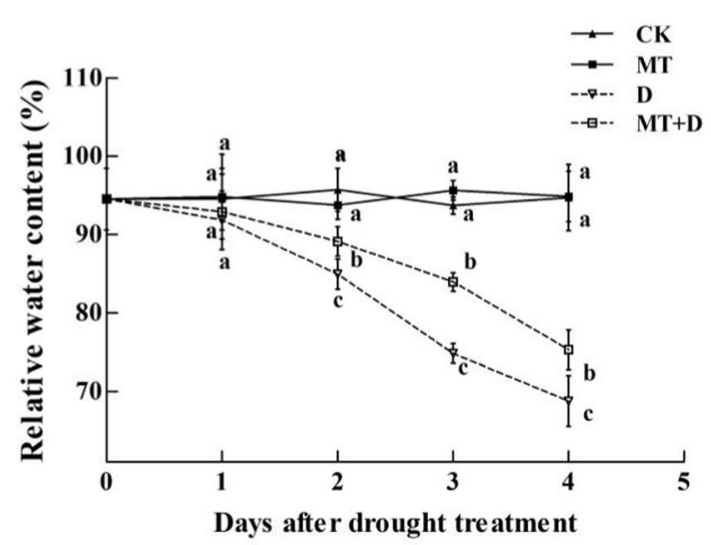

Fig. 1 Melatonin pretreatment alleviated the damage of maize seedling under drought stress. a Growth phenotype on day 3 and 4 for each treatment. b mean relative water content $(\%)$ of maize seedling leaves on day $1,2,3$ and 4 , respectively. Two seedlings were randomly selected per treatment and the third leaf was excised for determination. (i) control (CK): grown in Hoagland solution only; (ii) melatonin treatment (MT): pre-treated with $100 \mu \mathrm{mol} \mathrm{L}^{-1}$ melatonin then grown in Hoagland solution only; (iii) drought treatment (D): grown in Hoagland solution with $20 \%$ PEG-6000; and (iv) melatonin plus drought treatment $(\mathrm{MT}+\mathrm{D})$ : pre-treated with $100 \mu \mathrm{mol} \mathrm{\textrm {L } ^ { - 1 }}$ melatonin then grown in Hoagland solution with $20 \%$ PEG-6000. The data are expressed as the mean $\pm \mathrm{SD}$ of three independent biological replicates. Different lower cases letters indicate significant differences at the same time point $(P<0.05$; Duncan's multiple range test)

and $24.3 \%$, and biomass increased by $8.46,12.50,13.27$ and $11.39 \%$, respectively.

\section{Melatonin Increased the RWC of PEG-Treated Maize Seedling Leaves}

As shown in Fig. 1b, melatonin pre-treatment in the absence of PEG (MT) had no significant effect on the RWC of the maize seedling leaves, unlike PEG treatment (D), which had an increasing negative effect. When compared with CK, D treatment decreased the RWC of the leaves by $2.94,12.69$,
25.21 and $37.69 \%$ on day 1, 2, 3 and 4, respectively. Meanwhile, pre-treatment with melatonin under PEG-induced drought $(\mathrm{MT}+\mathrm{D})$ effectively improved the RWC of the leaves, with the most significant effect on day $3(12.17 \%$ increase compared to D treatment). These findings suggest that melatonin pre-treatment could improve the RWC of the leaves under drought conditions; thereby, helping maintain cell pressure.

\section{Melatonin Reduced the Level of Reactive-0xygen Species (ROS) in PEG-Treated Maize Seedling Leaves}

Levels of $\operatorname{ROS}\left(\mathrm{H}_{2} \mathrm{O}_{2}\right.$ and $\left.\mathrm{O}_{2}^{-}\right)$accumulation in the maize seedling leaves increased under PEG treatment; however, melatonin pre-treatment suppressed these levels (Fig. 2a, b). No significant differences were observed between CK and MT treatment, with the exception of $\mathrm{O}_{2}{ }^{-}$concentration on day 3. The accumulation of $\mathrm{H}_{2} \mathrm{O}_{2}$ and $\mathrm{O}_{2}^{-}$increased gradually with time under PEG-induced drought (D treatment), and although the changes were similar under MT $+\mathrm{D}$ treatment, the concentrations of $\mathrm{H}_{2} \mathrm{O}_{2}$ and $\mathrm{O}_{2}^{-}$were significantly lower. These findings suggest that pre-treatment with melatonin could reduce ROS levels under drought conditions.

\section{Melatonin Stimulated Antioxidant Activity in PEG-Treated Maize Seedling Leaves}

Melatonin pre-treatment under non-drought conditions (MT) had no effect on activities of SOD, CAT and POD. In contrast, PEG -treatment (D) stimulated activity of all three enzymes, while MT + D treatment did so further (Fig. 2c-e). When compared with D treatment, SOD activity increased by $17.77,15.36,24.35$ and $20.71 \%$, CAT activity increased by $16.32,23.02,41.88$ and $40.21 \%$, and POD activity increased by $19.29,10.25,23.81$ and $24.27 \%$ under MT + D on day 1,2, 3 and 4, respectively. The general trend in GSH levels was similar to that of SOD, CAT and POD (Fig. 2f), with an upward trend from days 1 to 4 under drought stress. When compared with D treatment, the GSH content of the leaves under MT $+\mathrm{D}$ treatment increased by $26.11,35.25$, 36.76 and $39.14 \%$ on day $1,2,3$ and 4 , respectively. These findings suggest that pre-treatment with melatonin could increase antioxidant activity under drought conditions.

\section{Melatonin Improved the Levels of Photosynthetic Pigment in PEG-Treated Maize Seedling Leaves}

Melatonin pre-treatment alone (MT) had no significant effects on chlorophyll $a(\mathrm{Chl} a), \mathrm{Chl} b$, carotenoid (Car) and total chlorophyll (Chl $t$ ) (Fig. 3); however, D treatment caused a significant decrease in all four parameters, especially on day 3 , with a reduction of $26.98,36.63$, 30.83 and $33.78 \%$, respectively, compared with CK. 
Table 1 Effects of melatonin on plant height, leaf length, leaf width and the dry weight of the shoots in PEG-treated

\begin{tabular}{llllll}
\hline Time & Treatment & Plant height $(\mathrm{cm})$ & Leaf length $(\mathrm{cm})$ & Leaf width $(\mathrm{cm})$ & $\begin{array}{l}\text { Dry weight of } \\
\text { shoot }(\mathrm{g} / \mathrm{plant})\end{array}$ \\
\hline $1 \mathrm{~d}$ & CK & $27.27 \pm 0.90 \mathrm{a}$ & $20.00 \pm 0.75 \mathrm{a}$ & $1.43 \pm 0.08 \mathrm{ab}$ & $0.219 \pm 0.009 \mathrm{a}$ \\
& MT & $28.40 \pm 0.66 \mathrm{a}$ & $19.50 \pm 0.66 \mathrm{a}$ & $1.45 \pm 0.13 \mathrm{a}$ & $0.231 \pm 0.004 \mathrm{a}$ \\
& D & $22.40 \pm 0.89 \mathrm{c}$ & $16.87 \pm 0.40 \mathrm{~b}$ & $1.27 \pm 0.03 \mathrm{~b}$ & $0.189 \pm 0.005 \mathrm{c}$ \\
& MT $+\mathrm{D}$ & $24.40 \pm 0.62 \mathrm{~b}$ & $17.77 \pm 0.85 \mathrm{~b}$ & $1.40 \pm 0.09 \mathrm{ab}$ & $0.205 \pm 0.009 \mathrm{~b}$ \\
2d & CK & $28.00 \pm 0.96 \mathrm{a}$ & $20.23 \pm 0.96 \mathrm{~b}$ & $1.50 \pm 0.09 \mathrm{a}$ & $0.234 \pm 0.007 \mathrm{a}$ \\
& MT & $29.23 \pm 0.85 \mathrm{a}$ & $21.53 \pm 0.70 \mathrm{a}$ & $1.48 \pm 0.03 \mathrm{a}$ & $0.233 \pm 0.004 \mathrm{a}$ \\
& D & $22.90 \pm 0.72 \mathrm{c}$ & $17.00 \pm 0.46 \mathrm{c}$ & $1.23 \pm 0.08 \mathrm{c}$ & $0.192 \pm 0.007 \mathrm{c}$ \\
& MT $+\mathrm{D}$ & $24.57 \pm 0.80 \mathrm{~b}$ & $18.40 \pm 0.50 \mathrm{~d}$ & $1.37 \pm 0.03 \mathrm{~b}$ & $0.216 \pm 0.009 \mathrm{~b}$ \\
$3 \mathrm{~d}$ & CK & $28.67 \pm 0.67 \mathrm{~b}$ & $20.70 \pm 0.95 \mathrm{a}$ & $1.52 \pm 0.03 \mathrm{a}$ & $0.237 \pm 0.009 \mathrm{a}$ \\
& MT & $30.13 \pm 0.38 \mathrm{a}$ & $21.97 \pm 0.57 \mathrm{a}$ & $1.57 \pm 0.03 \mathrm{a}$ & $0.245 \pm 0.009 \mathrm{a}$ \\
& D & $23.47 \pm 0.67 \mathrm{c}$ & $16.90 \pm 0.62 \mathrm{c}$ & $1.17 \pm 0.06 \mathrm{c}$ & $0.196 \pm 0.007 \mathrm{c}$ \\
& MT +D & $25.80 \pm 0.66 \mathrm{~d}$ & $18.60 \pm 0.62 \mathrm{~b}$ & $1.35 \pm 0.05 \mathrm{~b}$ & $0.222 \pm 0.006 \mathrm{~b}$ \\
$4 \mathrm{~d}$ & CK & $29.13 \pm 0.81 \mathrm{a}$ & $21.37 \pm 0.55 \mathrm{a}$ & $1.57 \pm 0.03 \mathrm{a}$ & $0.244 \pm 0.005 \mathrm{a}$ \\
& MT & $30.47 \pm 0.59 \mathrm{a}$ & $22.23 \pm 0.61 \mathrm{a}$ & $1.62 \pm 0.08 \mathrm{a}$ & $0.248 \pm 0.008 \mathrm{a}$ \\
& D & $23.70 \pm 0.46 \mathrm{c}$ & $16.40 \pm 0.56 \mathrm{c}$ & $1.07 \pm 0.12 \mathrm{c}$ & $0.202 \pm 0.006 \mathrm{c}$ \\
& MT +D & $26.17 \pm 0.91 \mathrm{~b}$ & $18.50 \pm 0.66 \mathrm{~b}$ & $1.33 \pm 0.03 \mathrm{~b}$ & $0.225 \pm 0.009 \mathrm{~b}$ \\
\hline
\end{tabular}

Values represent the mean \pm standard error of three replicates

Different lowercases letters indicate significant differences among treatments $(P<0.05$; Duncan's multiple range test)
Moreover, although each parameter was significantly lower under MT + D compared with CK treatment, the contents of Chl $a$, Chl $b$ and $\mathrm{Chl} t$ were significantly higher than under D treatment (increases of 17.61, 33.33 and $22.26 \%$, respectively). In contrast, there was no significant difference in Car between the two treatments. These findings suggest that pre-treatment with melatonin could alleviate chlorophyll degradation under drought conditions.

\section{Melatonin Improved Photosynthetic Gas Exchange Parameters in PEG-Treated Maize Seedling Leaves}

Photosynthetic gas-exchange parameters directly reflect the photosynthetic carbon assimilation ability. As shown in Fig. 4, melatonin pre-treatment alone (MT) had no significant effects on $P_{\mathrm{n}}, G_{\mathrm{s}}, C_{\mathrm{i}}$ or $T_{\mathrm{r}}$. In contrast, under $\mathrm{D}$ treatment, all four parameters decreased to a varying degree, with significant reductions compared to CK of $29.8,38.1,45.5$ and $47.4 \%$, respectively. Although $\mathrm{MT}+\mathrm{D}$ treatment also caused a significant reduction in all four parameters compared with CK, an increase of 22.02, 23.1, 30.2 and 13.5 was observed compared with $\mathrm{D}$ treatment, respectively. These findings suggest that pre-treatment with melatonin could significantly increase photosynthesis and gas exchange in maize seedling leaves under drought conditions, thereby helping maintain normal photosynthesis.

\section{Melatonin Changed the Stomatal Ultrastructure and Induced Stomatal Opening in PEG-Treated Maize Seedling Leaves}

The lower surfaces of the leaf samples were subsequently scanned under a SEM at $\times 1500$ magnification (Fig. 5a). Under control conditions (CK), the epidermal cells had a smooth surface and the stomata were arranged neatly, with semilunar stomatal guard cells and large apertures. No significant differences were observed under MT treatment; however, under D treatment, the epidermal cells became smaller and the guard cells contracted, and most of the stomata were closed. Meanwhile, melatonin pre-treatment $(\mathrm{MT}+\mathrm{D})$ effectively alleviated these PEG-induced effects, causing the stomata to reopen.

Melatonin pre-treatment alone (MT) had no significant effects on stomatal density, length, width or aperture size (Fig. 5b-e). However, in comparison, the density of the stomata increased by $34.5 \%$, the width decreased by $14.7 \%$, and the stomatal aperture decreased by about $79.7 \%$ under D treatment. In contrast, no significant differences in the length of the stomata were observed. Although MT $+\mathrm{D}$ treatment decreased the width of the stomata and reduced the stomatal aperture compared to CK, the aperture and width of stomatal increased by $197.36 \%$ and $8.04 \%$ compared with D treatment. These findings suggest that pretreatment with melatonin could improve stomatal conditions and induce stomatal reopening. 

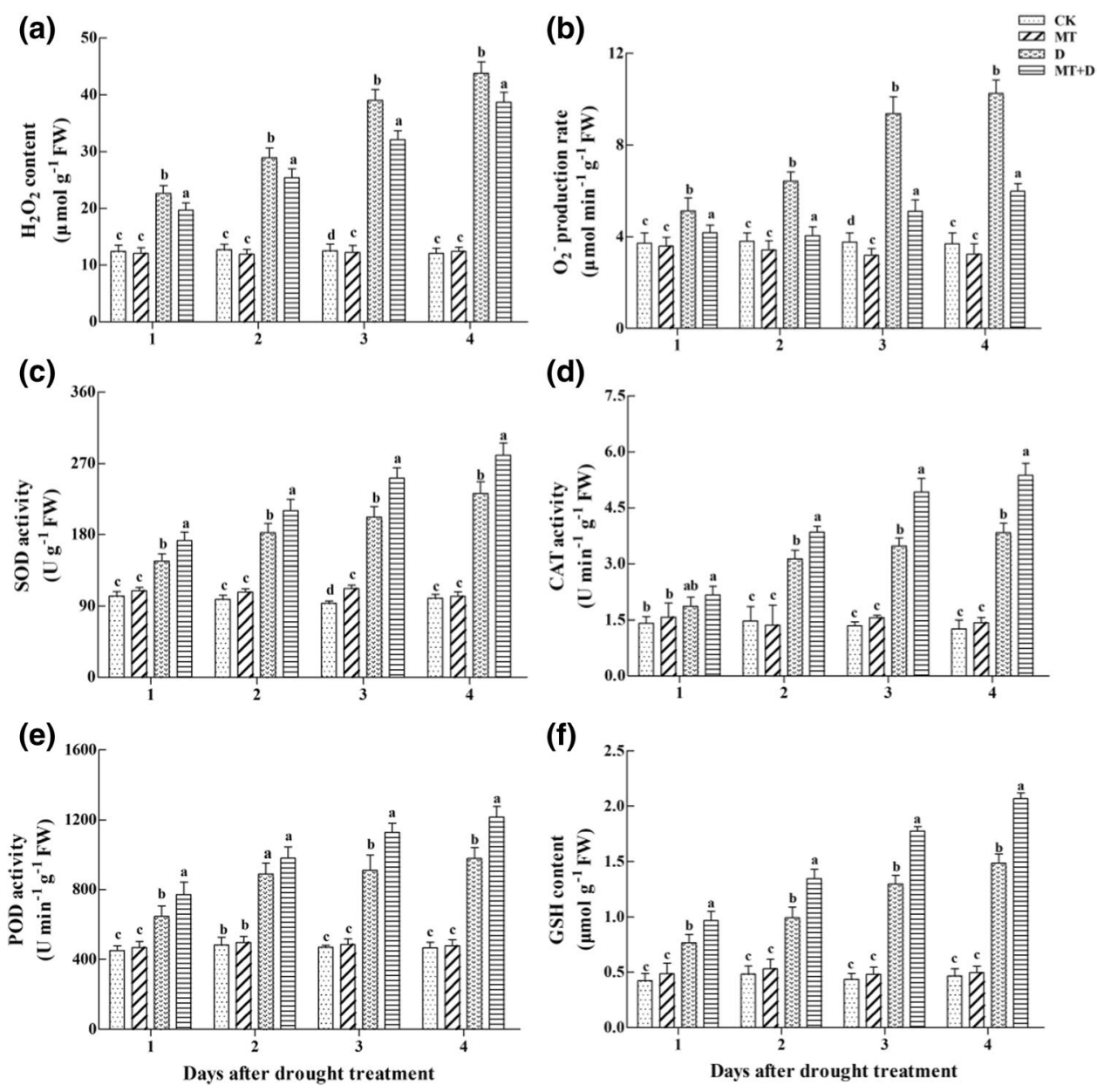

Fig. 2 Effects of melatonin on reactive-oxygen species (ROS) and antioxidant system in PEG-treated maize seedling leaves. a, b Mean levels of $\mathrm{H}_{2} \mathrm{O}_{2}$ (a) and $\mathrm{O}_{2}^{-}$(b) in maize seedling leaves under different treatments on day 1, 2, 3 and 4, respectively. c-f Mean levels of SOD (c), CAT (d), POD (e) and GSH (f) in maize seedling leaves under different treatments on day 1, 2, 3 and 4, respectively. (i) control (CK): grown in Hoagland solution only; (ii) melatonin treatment (MT): pre-treated with $100 \mu \mathrm{mol} \mathrm{L}^{-1}$ melatonin then grown in Hoagland solution only; (iii) drought treatment (D): grown in

\section{Exogenous Melatonin Decreased Abscisic Acid and Increased Endogenous Melatonin Levels in PEG-Treated Maize Seedling Leaves}

MT treatment significantly increased endogenous melatonin levels by $21.98 \%$ compared with the control (CK). Meanwhile, D treatment caused a significant increase in endogenous melatonin compared with $\mathrm{CK}$, while melatonin pre-treatment under PEG-induced drought $(\mathrm{MT}+\mathrm{D})$ caused a further improvement of $36.71 \%$ compared with D treatment (Fig. 6a). MT treatment had no effect on ABA levels (Fig. 6b), while D treatment caused a significant increase of $164.74 \%$. Meanwhile, MT + D treatment significantly suppressed this stress-related increase in ABA
Hoagland solution with 20\% PEG-6000; and (iv) melatonin plus drought treatment $(\mathrm{MT}+\mathrm{D})$ : pre-treated with $100 \mu \mathrm{mol} \mathrm{L}^{-1}$ melatonin then grown in Hoagland solution with 20\% PEG-6000. Two seedlings were randomly selected per treatment and the third leaf was excised for determination. The data are expressed as the mean $\pm \mathrm{SD}$ of three independent biological replicates. Different lowercase letters indicate significant differences among treatments $(P<0.05$; Duncan's multiple range test)

production, with a decrease of $30.12 \%$ compared with $\mathrm{D}$ treatment.

\section{Melatonin Decreased ABA Levels by Regulating the Expression of Genes Related to the ABA Metabolic Pathway in PEG-Treated Maize Seedling Leaves}

To validate the involvement of melatonin in the regulation of ABA metabolism, expression of ABA biosynthesis- and catabolism-related genes was examined. $\mathrm{D}$ treatment caused significant up-regulation of the NCEDI gene, with an 18.4fold increase in expression compared with CK on day 3 of PEG treatment. However, MT + D treatment significantly 


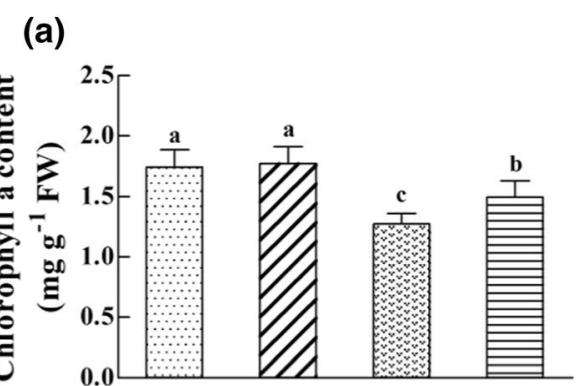

(c)

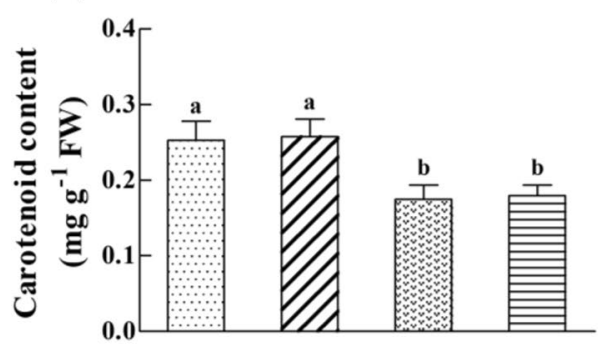

Fig. 3 Effects of melatonin on chlorophyll content in PEG-treated maize seedling leaves. a-d Mean levels of chlorophyll a (a), chlorophyll b (b), carotenoid (c) and total chlorophyll (d) in maize seedling leaves under different treatments on day 1,2, 3 and 4, respectively. (i) control (CK): grown in Hoagland solution only; (ii) melatonin treatment (MT): pre-treated with $100 \mu \mathrm{mol} \mathrm{\textrm {L } ^ { - 1 }}$ melatonin then grown in Hoagland solution only; (iii) drought treatment (D): grown in Hoagland solution with 20\% PEG-6000; and (iv) melatonin plus

suppressed up-regulation, with a decrease in the expression of $63.80 \%$ compared with D treatment (Fig. 6c). As shown in Fig. 6d-g, four ABA catabolism-related genes (ABA8oxla, $A B A 80 x 1 b, A B A 80 x 3 a$ and $A B A 80 x 3 b$ ) were down-regulated under D treatment, with a decreased in the expression of $16.42,76.55,67.26$ and $93.40 \%$, respectively, compared with CK. In contrast, MT + D treatment caused a significant 2.2-, 3.1- and 12.3-fold increase in ABA8oxlb, ABA8ox $3 a$ and $A B A 80 x 3 b$ expression, but a decrease in $A B A 80 x 1 a$ expression of $36.83 \%$ compared with D treatment.

\section{Discussion}

It is well known that drought stress adversely effects physiological and biochemical processes in plants, leading to a reduction in overall productivity (Reddy et al. 2004; Sanchita et al. 2015). As higher plants, they have developed different strategies to response various environmental stress (Kim and Kim 2020). Melatonin, as a kind of new plant growth regulator, is thought to be involved in abiotic stress responses (Zhang et al. 2015). In our study, the positive protective role of melatonin in maize seedlings against drought stress was investigated. The PEG-induced drought stress

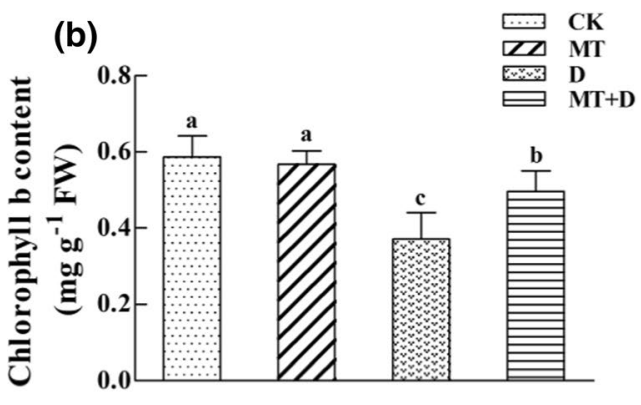

(d)

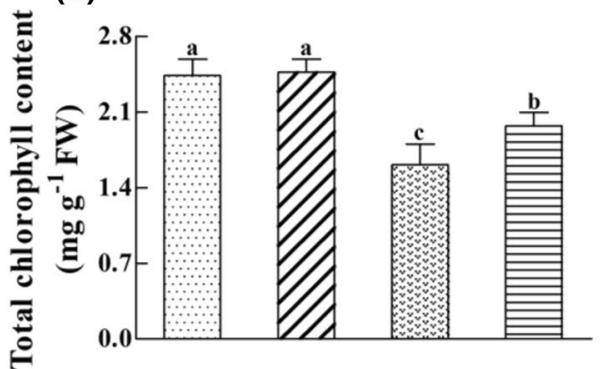

drought treatment $(\mathrm{MT}+\mathrm{D})$ : pre-treated with $100 \mu \mathrm{mol} \mathrm{\textrm {L } ^ { - 1 }}$ melatonin then grown in Hoagland solution with 20\% PEG-6000. Two seedlings were randomly selected per treatment and the third leaf was excised for determination. The data are expressed as the mean \pm SD of three independent biological replicates. Different lowercase letters indicate significant differences among treatments $(P<0.05$; Duncan's multiple range test)

caused a decrease in the leaf area and relative water content of maize seedlings, and the severity of these effects was intensified with time. Meanwhile, melatonin pre-treatment significantly improved both parameters under drought stress (Table 1, Fig. 1). Ye et al. (2016) reported that $100 \mu \mathrm{m}$ melatonin pertreatment improved the shoot dry weight and leaf area of maize seedlings under drought stress, which is consistent with our results. In the present study, it is worth noting that melatonin-treated plants maintained higher biomass especially on the third day (Table 1), which is constant with the trend of relative water content, suggesting that melatonin may enhance plant root water uptake ability and alleviate the inhibitory effects of drought on maize seedling growth.

Photosynthesis occurs in the chloroplasts, which is also the leaf organelle that is most sensitive to abiotic stress. They are also the main site of ROS generation in plant cells. The chlorophyll content of the chloroplast therefore largely determines whether a plant is under good growth conditions as well as the photosynthetic capacity of the leaves (Pandey et al. 2009; Shapiguzov et al. 2012; Croft et al. 2017). Drought can induce accumulation of ROS in plants, with excessive ROS promoting chlorophyll degradation and reducing the chlorophyll content (Yordanov et al. 2000). In this study, drought stress caused a significant 


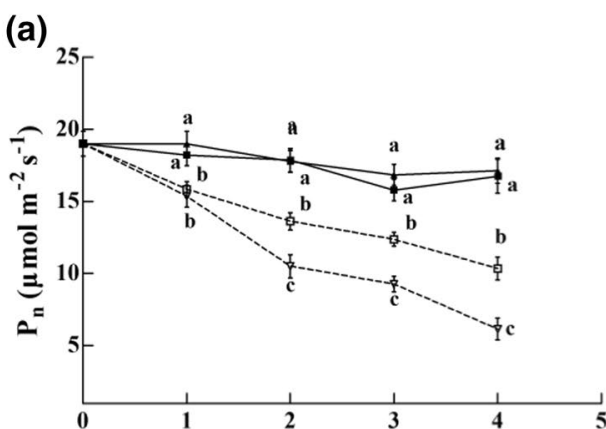

(c)

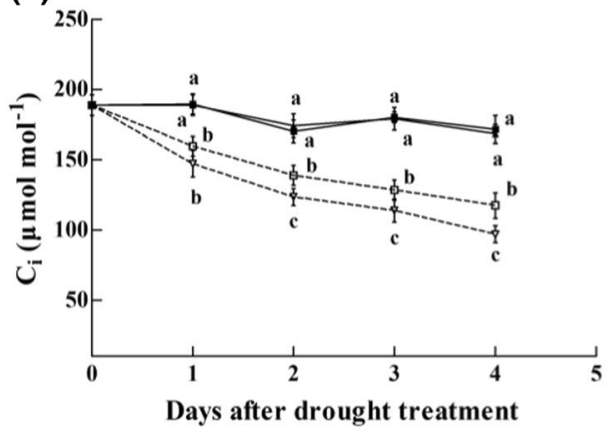

Fig. 4 Effects of melatonin on gas exchange in PEG-treated maize seedling leaves. a-d Mean levels of Pn (a), Gs (b), Ci (c) and $\operatorname{Tr}(\mathbf{d})$ in maize seedling leaves under different treatments on day 1, 2, 3 and 4, respectively. (i) control (CK): grown in Hoagland solution only; (ii) melatonin treatment (MT): pre-treated with $100 \mu \mathrm{mol} \mathrm{L}{ }^{-1}$ melatonin then grown in Hoagland solution only; (iii) drought treatment (D): grown in Hoagland solution with 20\% PEG-6000; and (iv) melatonin

increase in $\mathrm{H}_{2} \mathrm{O}_{2}$ and $\mathrm{O}_{2}^{-}$, as a result, the chlorophyll content of the leaves was lower than under control conditions (Fig. 3). However, melatonin pre-treatment reduced the $\mathrm{H}_{2} \mathrm{O}_{2}$ and $\mathrm{O}_{2}{ }^{-}$content, as well as improving chlorophyll levels. These findings suggest that melatonin acts as an antioxidant, directly reducing ROS levels and inhibiting chlorophyll degradation (Tan et al. 2007; Ma et al. 2018). There is further evidence that melatonin reduces the degradation of chlorophyll by down-regulating expression of chlorophyll degradation-related genes during MeJA-induced senescence (Wang et al. 2019b). SOD, POD and CAT are important protective enzymes in the enzymatic defense system, effectively decreasing levels of $\mathrm{H}_{2} \mathrm{O}_{2}$ and decomposing ROS. Moreover, GSH is an important non-enzymatic antioxidant, scavenging $\mathrm{O}_{2}{ }^{-}$and reducing oxidative damage under stressful conditions. Activity of all four components therefore ensures stress tolerance in plants, including those subjected to long-term drought stress (Liu et al. 2009; Kang et al. 2013). In this study, antioxidant enzyme activity (SOD, POD and CAT) and the GSH content of the maize seedling leaves increased significantly, mainly due to the response of maize seedlings to drought stress (Anjum et al. 2017). Meanwhile, pre-treatment with melatonin further improved

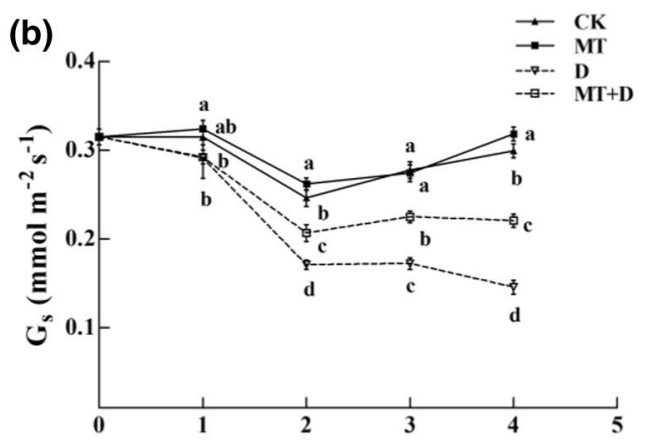

(d)

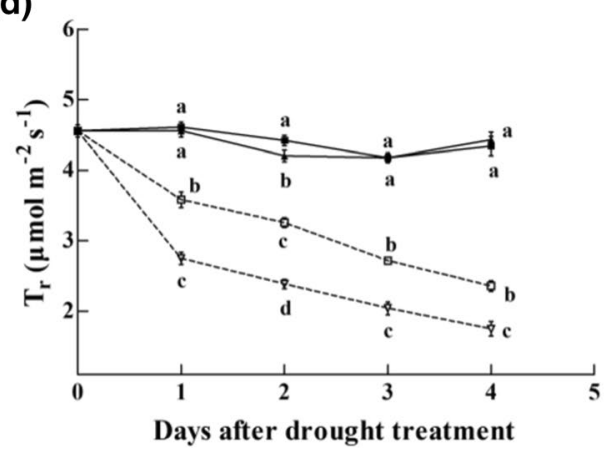

plus drought treatment $(\mathrm{MT}+\mathrm{D})$ : pre-treated with $100 \mu \mathrm{mol} \mathrm{L}{ }^{-1}$ melatonin then grown in Hoagland solution with 20\% PEG-6000. Two seedlings were randomly selected per treatment and the third leaf was excised for determination. The data are expressed as the mean \pm SD of three independent biological replicates. Different lowercase letters indicate significant differences among treatments $(P<0.05$; Duncan's multiple range test)

antioxidant enzyme activity and GSH levels under drought conditions (Fig. 2c-f), increasing ROS clearance (Fig. 2a, b). These findings suggest that pre-treatment with exogenous melatonin reduced ROS accumulation by further activating the antioxidant defense system and alleviating oxidative damage in maize seedlings under drought stress.

Important physiological processes in the leaves, such as respiration, photosynthesis and transpiration, are regulated by stomata, the opening and closing of which is regulated by water balance and complex signal transduction pathways (Gray 2005; Zou and Kahnt 2008). When subjected to drought stress, plants maintain their cellular moisture content by regulating stomatal closure and reducing the transpiration rate (Schroeder et al. 2001). In this study, the lower surfaces of the leaves were scanned at $\times 1500$ magnification, revealing a significant decrease in the lengths and widths of the stomata under drought stress, as well as a decrease in the aperture opening (Fig. 5a). However, stomatal density increased significantly under drought stress, with contraction of the guard cells. Moreover, pre-treatment with melatonin increased the stomatal length and width under drought stress, although measurements were lower than in the control leaves (Fig. 5b-e). In contrast to our findings, Li et al. (2015) 
Fig. 5 Effects of melatonin on the stomatal of PEG-treated maize seedling leaves. a The scanning electron microscopy (SEM) images of seedling leaves on the third day of drought treatment. b-e Mean levels of stomatal density (b), stomatal length (c), stomatal width (d) and stomatal aperture (e) in maize seedling leaves under different treatments on the third day. (i) control (CK): grown in Hoagland solution only; (ii) melatonin treatment (MT): pre-treated with $100 \mu \mathrm{mol} \mathrm{L}{ }^{-1}$ melatonin then grown in Hoagland solution only; (iii) drought treatment (D): grown in Hoagland solution with 20\% PEG-6000; and (iv) melatonin plus drought treatment $(\mathrm{MT}+\mathrm{D})$ : pre-treated with $100 \mu \mathrm{mol} \mathrm{L}^{-1}$ melatonin then grown in Hoagland solution with 20\% PEG-6000.

Two seedlings were randomly selected per treatment and the third leaf was excised for determination. The data are expressed as the mean $\pm \mathrm{SD}$ of three independent biological replicates. Different lowercase letters indicate significant differences among treatments $(P<0.05$; Duncan's multiple range test) (a)

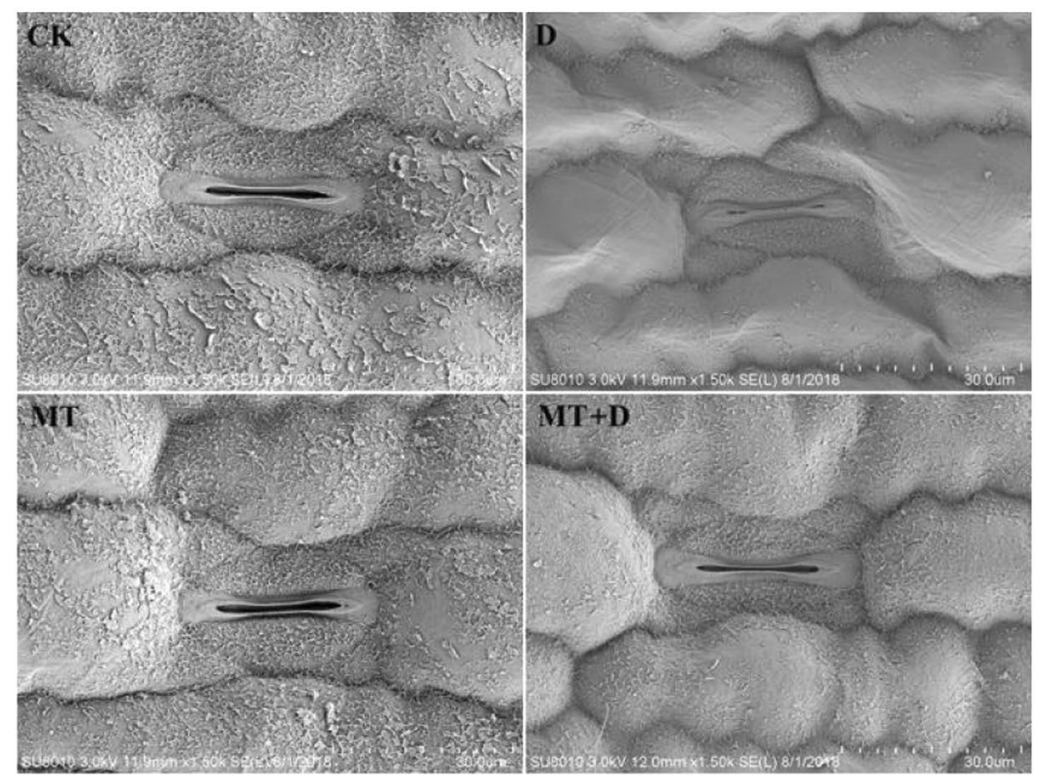

(b)

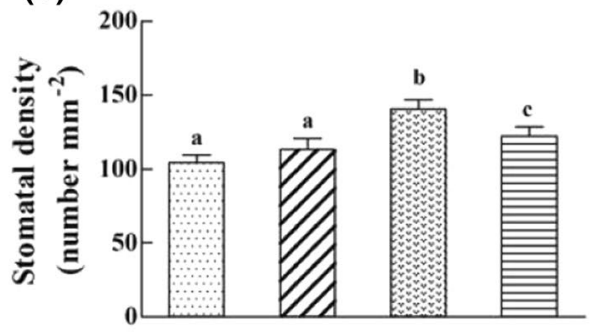

(d)

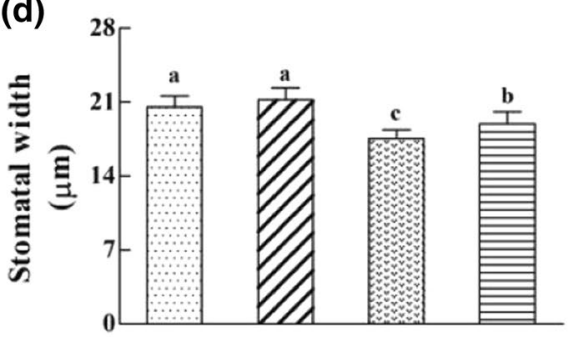

(c)

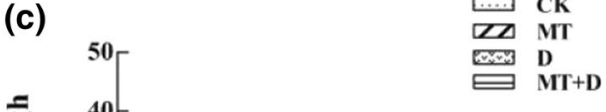

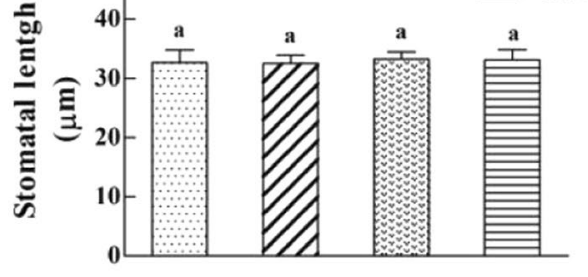

(e)

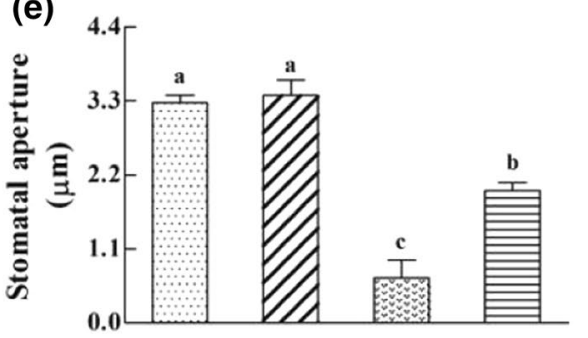

suggested that drought did not alter the stomatal density in apple leaves, however, pre-treatment with exogenous melatonin did maintain high turgor pressure and keep the stomata open. Similarly, Meng et al. (2014) revealed no obvious differences in the stomatal aperture between grape plants pretreated with melatonin and stressed control plants. Although not completely consistent with our findings, this may be due to differences in the regulatory mechanism of melatonin in different species.

ABA is an important plant hormone that plays pivotal roles in conferring tolerance to various environmental stressors (Fujita et al. 2005). It is involved in a number of physiological processes, such as plant growth and development, responses to abiotic stress and regulation of stomatal closure (Finkelstein et al. 2002; Timothy and Brodribb
2013). Stress stimulates the accumulation of ABA in plants, reducing transpiration by regulating stomatal closure to prevent cellular water losses (Zhang et al. 2006). Studies have shown that ABA levels in plants are associated with genes involved in ABA synthesis and degradation, such as NCEDI (ABA biosynthesis), ABA8oxl and ABA8ox2 (ABA catabolism) (Li et al. 2015). Our study focused on ABA biosynthesis and metabolic pathways. PEG-induced drought stress significantly increased ABA levels in maize seedling leaves (Fig. 6b). Consistently, the expression of $N C E D 1$ was also significantly up-regulated, while expression of $A B A 80 x 1$ and $A B A 80 x 3$ was significantly down-regulated. Meanwhile, melatonin pretreatment repressed NCEDI up-regulation and selectively up-regulated $A B A 80 x 1$ and $A B A 80 x 3$, ultimately reducing 
Fig. 6 Effects of melatonin on endogenous melatonin, abscisic acid content and expression of key ABA synthesis and metabolism-related genes in PEG-treated maize seedling leaves. a, b Mean levels of endogenous melatonin (a) and abscisic acid (b) in maize seedling leaves under different treatments on the third day. C-G Mean expression of $N C E D 1$ gene (c), $A B A 8 o \times 1 a$ (d), $A B A 8 o \times 1 b(\mathbf{e}), A B A 8 o \times 3 a$ (f) and $A B A 8 o \times 3 b(\mathbf{g})$ in maize seedling leaves under different treatments on the third day. (i) control (CK): grown in Hoagland solution only; (ii) melatonin treatment (MT): pre-treated with $100 \mu \mathrm{mol}$ $\mathrm{L}^{-1}$ melatonin then grown in Hoagland solution only; (iii) drought treatment (D): grown in Hoagland solution with $20 \%$ PEG-6000; and (iv) melatonin plus drought treatment $(\mathrm{MT}+\mathrm{D})$ : pre-treated with $100 \mu \mathrm{mol} \mathrm{L}-1$ melatonin then grown in Hoagland solution with 20\% PEG-6000. Two seedlings were randomly selected per treatment and the third leaf was excised for determination. The data are expressed as the mean \pm SD of three independent biological replicates. Different lowercase letters indicate significant differences among treatments $(P<0.05$; Duncan's multiple range test)
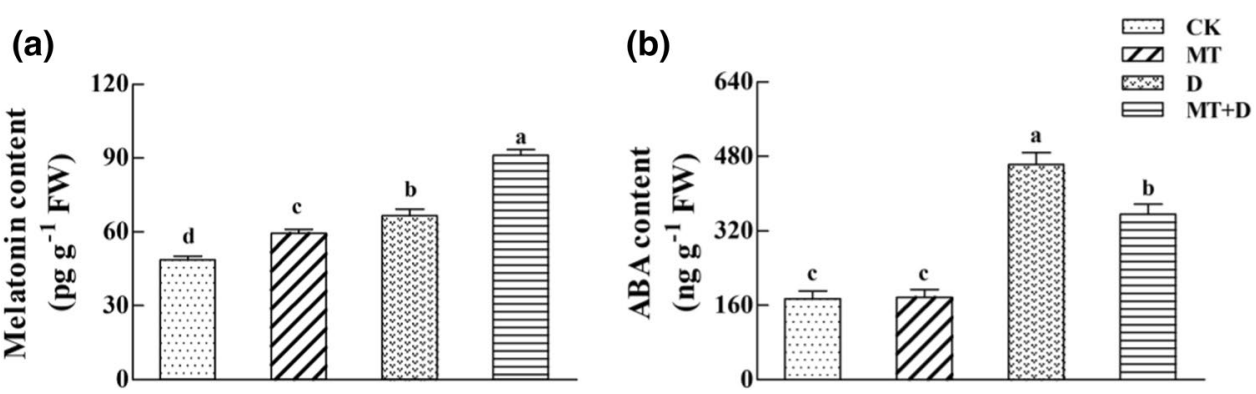

(c)

(d)

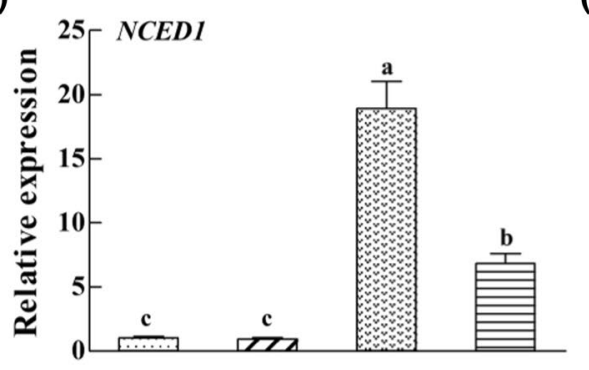

(e)

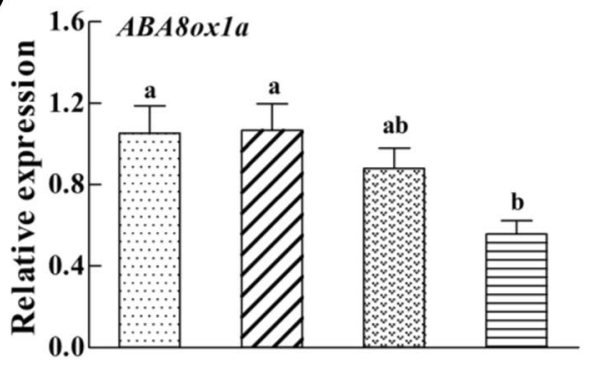

(f)
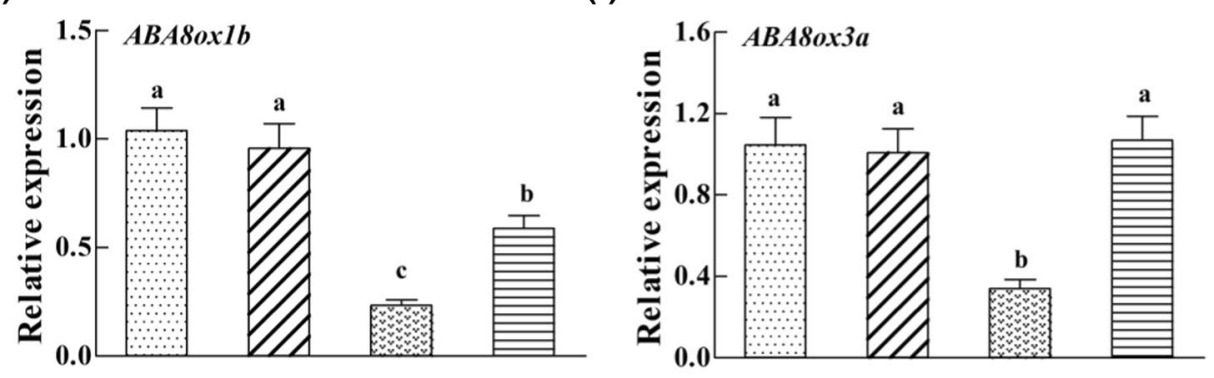

(g)

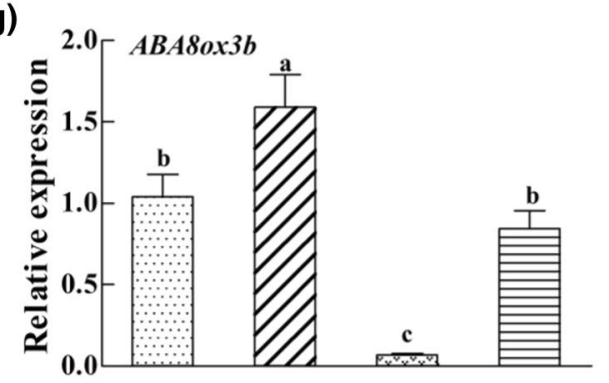

ABA levels (Figs. 6c-g). These findings suggest that melatonin acts as a negative regulator of ABA biosynthesis, inducing stomatal reopening by regulating ABA metabolism ( $\mathrm{Li}$ et al. 2015). In addition, analysis of endogenous melatonin levels in the maize seedling leaves revealed a much higher level after melatonin pre-treatment compared with control plants. This suggests that exogenously applied melatonin promotes biosynthesis of melatonin de novo via increased expression of melatonin biosynthesisrelated genes (Zheng et al. 2017). More notable is that endogenous melatonin in the leaves of plants pre-treated with exogenous melatonin was $21.98 \%$ higher than that in the control plants, while under drought stress, levels were $36.71 \%$ higher after pre-treatment with melatonin than under drought stress (Fig. 6a). These findings suggest lead us to the following hypothesis: under drought stress, exogenous melatonin induces stomatal re-opening via regulation of $\mathrm{ABA}$ metabolism, thereby restoring transpiration and active transport. The bioactive melatonin molecules are subsequently transported via an active transport mechanism or specialized channel (Erland et al. 2018), subsequently increasing levels of endogenous melatonin. Further studies are now needed to confirm this hypothesis. 


\section{Conclusions}

To summarize, this study suggests that melatonin mitigates photosynthetic damage in maize seedling under drought stress in two ways: (i) by maintaining a high water content in the leaves and enhancing the antioxidant system, thereby effectively reducing the accumulation of ROS, preventing chlorophyll degradation and maintaining photosynthesis; (ii) by significantly promoting ABA decomposition and inhibiting synthesis, thereby reducing accumulation, inducing stomatal reopening and helping maintain photosynthesis. A schematic representation of this hypothesis is provided in Fig. 7. Overall, therefore, the results of this study provide preliminary evidence that melatonin protects photosynthesis and enhances drought tolerance in maize seedlings under drought stress.

\section{Materials and methods}

\section{Experimental Materials}

Zhengdan 958, a widely used maize (Zea mays L.) cultivar in China, was used in this study. Uniform seeds were selected to accelerate germination in a greenhouse at $25^{\circ} \mathrm{C}$. After germination, the seedlings were placed in an artificial climate chamber ( $75 \%$ humidity, $25 / 15{ }^{\circ} \mathrm{C}$ day/night) and grown via hydroponics in Hoagland solution. Light was provided by sodium lamps during a 14-h photoperiod (photon flux density of $400 \mu \mathrm{mol} \mathrm{m} \mathrm{m}^{-2}$ ). The nutrient solution was changed daily.

\section{Experimental Design}

Preliminary experiments were conducted to determine the optimal melatonin concentration. Leaves were sprayed with five concentrations of melatonin $(0,50,100,150$ and $200 \mu \mathrm{mol} \mathrm{L}^{-1}$ ) once a day for 4 consecutive days then before treatment with PEG for four days. The rate of photosynthesis under each concentration was then measured. Based on this preliminary experiments, $100 \mu \mathrm{mol} \mathrm{L}{ }^{-1}$ melatonin was selected for the final experimentation. When seedlings reached the trifoliate stage, half of all uniformly growing plants were sprayed with $100 \mu \mathrm{mol} \mathrm{L}^{-1}$ melatonin at 8:00 am and 20:00 pm daily for 5 consecutive days. The remaining plants were treated with distilled water as a control at the same time points. After a pre-cultivation period, the control and melatonin pre-treated seedlings were each randomly divided into two subgroups: normal control and
Fig. 7 Regulatory effect of melatonin on photosynthesis in maize seedlings under drought stress

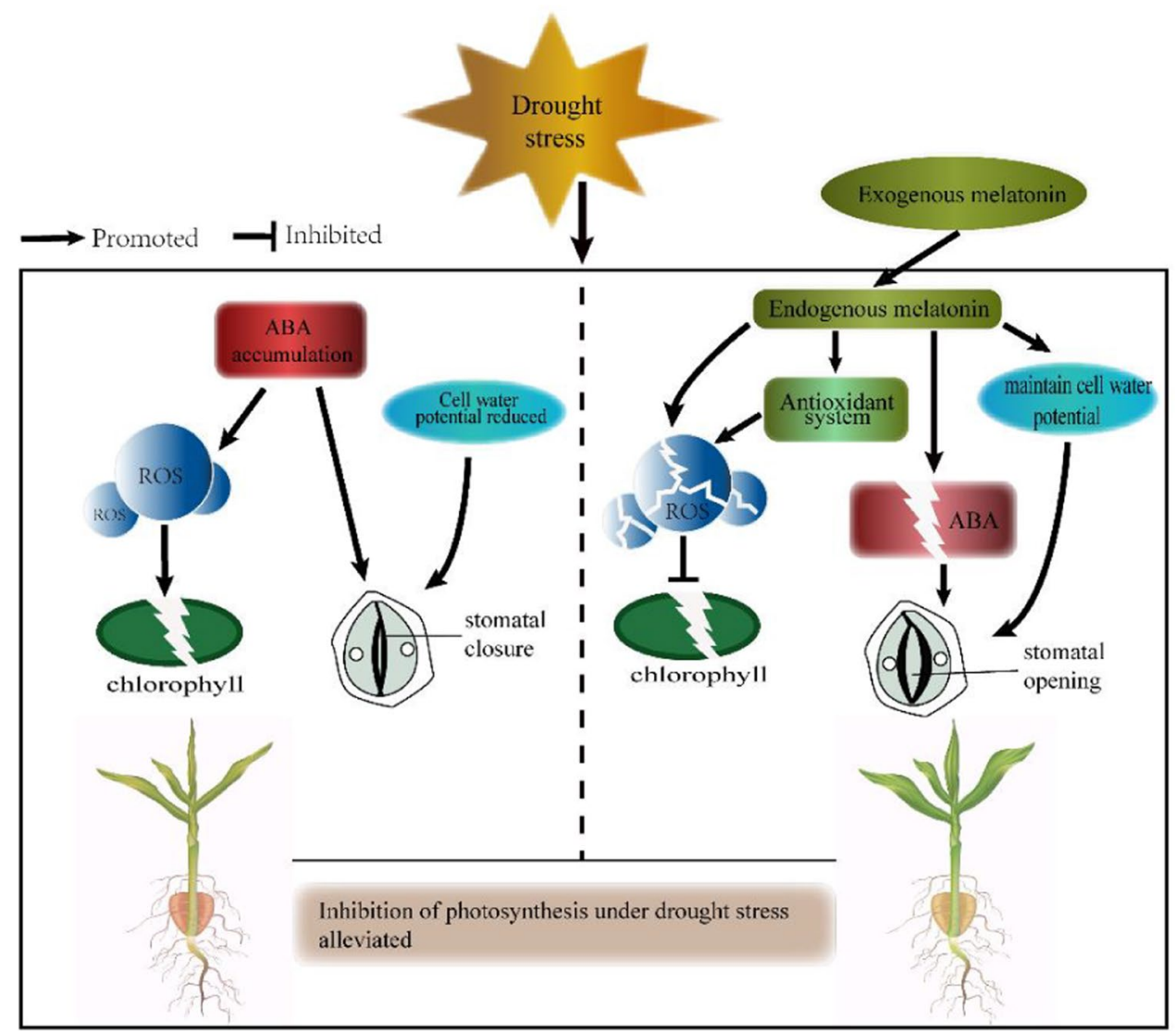


drought treatment. Under drought treatment, 20\% PEG6000 was used to induce drought treatment for four days. A total of four treatments were therefore examined: (i) control (CK): grown in Hoagland solution only; (ii) melatonin treatment (MT): pre-treated with $100 \mu \mathrm{mol} \mathrm{L}^{-1}$ melatonin then grown in Hoagland solution only; (iii) drought treatment (D): grown in Hoagland solution with 20\% PEG-6000; and (iv) melatonin plus drough treatment $(\mathrm{MT}+\mathrm{D})$ : pre-treated with $100 \mu \mathrm{mol} \mathrm{L-1}$ melatonin then grown in Hoagland solution with 20\% PEG-6000. Each treatment was carried out in triplicate with 36 seedlings per treatment. Seedlings were observed after 1, 2, 3 and 4 days of treatment, and third leaves from the bottom of the stem were sampled for subsequent analysis.

\section{Measurement of Plant Traits}

Plants were collected from each treatment group (CK, MT, $\mathrm{D}, \mathrm{MT}+\mathrm{D})$ after 1, 2, 3 and 4 days treatment for measurement of plant height, leaf length and width and dry weight. Plant height was determined as the height of the aboveground part using a ruler. Leaf length and width were determined as the maximum length and width of the third leaf using a ruler. The dry weight of the aboveground tissues was determined after drying in an oven at $80{ }^{\circ} \mathrm{C}$ until a constant weight was reached. At least three independent biological replications were performed for each experiment.

\section{Measurement of RWC}

The RWC was estimated according to the method of Gaxiola et al. (2001). Briefly, two seedlings were randomly selected per treatment and the third leaf was excised, divided into two equal parts then the fresh weights $\left(F_{\mathrm{w}}\right)$ of each were recorded immediately. One part was floated in deionized water for $12 \mathrm{~h}$ then the rehydrated weight $\left(S_{\mathrm{w}}\right)$ was determined. The remaining part was oven-dried at $70{ }^{\circ} \mathrm{C}$ until reaching a constant weight then the dry weight was determined $\left(D_{\mathrm{w}}\right)$. The RWC was then calculated as follows:

$(\mathrm{RWC})=\left(F_{\mathrm{w}}-D_{\mathrm{w}}\right) /\left(S_{\mathrm{w}}-D_{\mathrm{w}}\right) \times 100 \%$,

\section{Measurement of $\mathrm{H}_{2} \mathrm{O}_{2}$ and $\mathrm{O}_{2}{ }^{-}$}

The production rate of superoxide $\mathrm{O}_{2}{ }^{-}$was determined as described by Schneider et al. (1981). Briefly, the fresh samples of the third leaf $(0.5 \mathrm{~g})$ were homogenized with $65 \mathrm{mM}$ phosphate buffer ( $\mathrm{pH}$ 7.8) then centrifuged at $5000 \mathrm{~g}$ for $15 \mathrm{~min}$ at $4{ }^{\circ} \mathrm{C}$. Next, $0.5 \mathrm{~mL}$ supernatant, $0.5 \mathrm{~mL}$ phosphate-buffered saline (PBS; $65 \mathrm{mM}, \mathrm{pH} 7.8$ ) and $1.0 \mathrm{~mL}$ $10 \mathrm{mM}$ hydroxylamine hydrochloride were mixed together and incubated at $25^{\circ} \mathrm{C}$ for $1 \mathrm{~h}$ before adding $1.0 \mathrm{~mL} 17 \mathrm{mM}$ p-aminobenzene sulfonic acid and $1.0 \mathrm{~mL} 7.0 \mathrm{mM}$ naphthylamine to the mixture and incubating at $25{ }^{\circ} \mathrm{C}$ for a further $20 \mathrm{~min}$. The change in absorbance at $530 \mathrm{~nm}$ was then determined. A standard curve of $\mathrm{NO}_{2}^{-}$was used to calculate the production rate of $\mathrm{O}_{2}{ }^{-}$from the chemical reaction of $\mathrm{O}_{2}^{-}$and hydroxylamine, while the $\mathrm{H}_{2} \mathrm{O}_{2}$ content was assayed according to Thordal-Christensen et al. (1997).

\section{Measurement of Antioxidant Activity}

Superoxide dismutase (SOD) activity was determined using the nitro blue tetrazolium (NBT) illumination method (Kakkar et al. 1984). The amount of enzyme required for $1 \mathrm{mg}$ of tissue protein in $1 \mathrm{ml}$ of reaction mixture to raise the SOD inhibition rate to $50 \%$ at $550 \mathrm{~nm}$ was defined as SOD activity. Peroxidase (POD) activity was determined according to the method of Upadhyaya et al. (1985). whereby the absorbance of reaction mixture containing $30 \mu \mathrm{l}$ enzyme extract, $50 \mathrm{mM}$ phosphate buffer ( $\mathrm{pH} 7.8$ ), guaiacol and $30 \%$ $\mathrm{H}_{2} \mathrm{O}_{2}$ was recorded then the amount of enzyme required to change the absorbance by 0.01 was defined as POD activity. Catalase (CAT) activity was assayed according to Hamurcu et al. (2013), whereby one unit of CAT activity was determined as the amount of enzyme required to decompose $1 \mu \mathrm{mol} \mathrm{H}_{2} \mathrm{O}_{2}$ at $405 \mathrm{~nm} \mathrm{~s}^{-1}$ in $1 \mathrm{mg}$ fresh tissue protein. The glutathione (GSH) content was measured according to the method of Ma and Cheng (2003).

\section{Measurement of Gas Exchange Parameters}

Gas exchange parameters [the rate of photosynthetic $\left(P_{\mathrm{n}}\right)$, stomatal conductance $\left(G_{\mathrm{s}}\right)$, transpiration rate $\left(T_{\mathrm{r}}\right)$ and intercellular $\mathrm{CO}_{2}$ concentration $(\mathrm{Ci})$ ] were recorded using the fully expanded third leaf at 10:00 am with a portable photosynthesis system (LI-6400XT; LI-COR Biosciences, Lincoln, NE, USA). A $6 \mathrm{~cm}^{2}(2 \times 3)$ leaf chamber was used to carry out measurements at $1000 \mu \mathrm{mol}$ photons $\mathrm{m}^{-2} \mathrm{~s}^{-1}$, with a constant airflow rate of $500 \mu \mathrm{mol} \mathrm{s}^{-1}, \mathrm{a} \mathrm{CO}_{2}$ concentration of $450 \mu \mathrm{mol} \mathrm{mol}^{-1}$ and $60 \%$ relative humidity. Each treatment was carried out in triplicate.

\section{Measurement of Chlorophyll Concentrations}

The chlorophyll content was determined according to the method of Arnon (1949) with slight modifications. Briefly, the third leaf samples were selected from each treatment and cut up then soaked in a graduated tube with $80 \%$ acetone to prevent light from affecting the results. When chlorophyll extraction was complete. The supernatant was then separated and placed in a new tube, and absorbance was recorded at wavelengths of 663, 645 and $470 \mathrm{~nm}$ to determine chlorophyll a (Chl $a), \mathrm{Chl} b$, carotenoid (Car) content. As a blank control, $80 \%$ acetone was used. 
Table 2 Primers used for qRTPCR analysis

\begin{tabular}{lll}
\hline Gene name & Forward primer $\left(5^{\prime}-3^{\prime}\right)$ & Reverse primer $\left(5^{\prime}-3^{\prime}\right)$ \\
\hline NCED 1 & CCACGCACACCAGAGTTACA & GCTGGGCGCCTTTCTACTAA \\
ABA8oxla & ATGCTCGTGCTCTTCCACCACCT & TATACCGCCATACCATATCCATCCGCC \\
ABA8ox1b & ATGCTCGTGCTCTTCCACCACCT & GGAAGCGGTTTTTCGCGTTCCTGG \\
ABA8ox3a & ACAGAAAGGGGCGTGAGACCGA & AGGCGAGCAAAGAAGAATTTCAA \\
ABA8ox3b & ACAGAAATGGCCGCCATGAGACCGA & ATTTCTTCTCCCCCTCAAGGTAAT \\
\hline
\end{tabular}

\section{Observations of Stomata via Scanning Electron Microscopy}

On the third day of drought treatment, one seedling was selected per treatment and third leaf samples were cut into $1 \times 2 \mathrm{~mm}$ rectangular pieces and immediately fixed in $4 \%$ glutaraldehyde solution with 0.1 M PBS (pH 7.4). After rinsing five times in PBS, they were then dehydrated in a graded ethanol series, dried to the critical point of $\mathrm{CO}_{2}$ and gold coated. The stomata were then observed under a JSM-6360LV microscope (JEOL Ltd., Tokyo, Japan).

\section{Measurement of Endogenous Melatonin and Abscisic Acid}

First, $0.1 \mathrm{~g}$ maize leaf was were ground into powder with liquid nitrogen and extracted with $1.0 \mathrm{mM}$ phosphate buffer (pH 7.4) in $1.5 \mathrm{~mL}$ centrifuge tube. Secondly, the mixed sample was placed on ice for $1 \mathrm{~min}$, then centrifuged at $4{ }^{\circ} \mathrm{C}$ for $20 \mathrm{~min}$ at $10,000 \times g$ and collect supernatant. The contents of endogenous melatonin and abscisic acid were assayed using a melatonin enzyme-linked immunosorbent assay (ELISA) kit (ml024033; Mlbio, Shanghai, China) and plant hormone abscisic acid (ABA) ELISA kit (ml-E2607; Mlbio, Shanghai, China) according to the manufacturer's instructions, respectively.

\section{qRT-PCR Analysis}

Total RNA was extracted from the leaves according to the methods of Faccioli et al. (1995). Primer sequences were obtained from the GeneBank database and specific primers were designed using Primer Express Software v2.0 (Biosoft International, Palo Alto, CA, USA). $\beta$-actin was used as a reference gene. All primers used are listed in Table 2. QRT-PCR was carried out on an ABI ViiA 7 Real-Time PCR System using ABI SYBR $®$ Select Master Mix (4,472,908, Mingyangkehua BioTechnology Co., Ltd, Beijing). Two technical repeats were carried for each sample. Relative expression levels were then calculated using the $2^{-\Delta \Delta \mathrm{Cp}}$ method (Livak and Schmittgen 2001).

\section{Statistical Analysis}

An one-way analysis of variance (ANOVA) was carried out using SPSS 17.0 software (IBM, Armonk, NY, USA). Multiple pairwise comparisons using Duncan's multiple range tests at $\alpha=0.05$ were used to determine significant differences among treatments. mks were generated with Origin 9.0 (OriginLab, Northampton, MA, USA) and standard errors of the means were calculated and presented in each graph. The regulatory network was generated using Adobe Illustrator 5.1 (Adobe Systems Inc., San Jose, California, USA).

Acknowledgements We gratefully acknowledge the College of Agronomy, Henan Agricultural University, for providing the laboratory of this study. We sincerely thank the reviewers for their helpful comments and supplementary proposal.

Funding This work was supported by the National Key Research and Development Program of China (Grant Numbers 2016YFD0100500 and 2016YFD0100503).

\section{Compliance with Ethical Standards}

Conflicts of Interest The authors declare no conflict of interest.

Open Access This article is licensed under a Creative Commons Attribution 4.0 International License, which permits use, sharing, adaptation, distribution and reproduction in any medium or format, as long as you give appropriate credit to the original author(s) and the source, provide a link to the Creative Commons licence, and indicate if changes were made. The images or other third party material in this article are included in the article's Creative Commons licence, unless indicated otherwise in a credit line to the material. If material is not included in the article's Creative Commons licence and your intended use is not permitted by statutory regulation or exceeds the permitted use, you will need to obtain permission directly from the copyright holder. To view a copy of this licence, visit http://creativecommons.org/licenses/by/4.0/.

\section{References}

Anjum SA, Wang LC, Farooq M, Hussain M, Xue LL, Zou CM (2011) Brassinolide application improves the drought tolerance in maize through modulation of enzymatic antioxidants and leaf gas exchange. J Agron Crop Sci 197(3):177-185 
Anjum SA, Ashraf U, Tanveer M, Khan I, Hussain S, Shahzad B, Zohaib A, Abbas F, Saleem MF, Ali I, Wang LC (2017) Drought induced changes in growth, osmolyte accumulation and antioxidant metabolism of three maize hybrids. Front Plant Sci 8:69-69

Arnao MB, Hernandezruiz J (2014) Melatonin: plant growth regulator and/or biostimulator during stress? Trends Plant Sci 19(12):789-797

Arnao MB, Hernandezruiz J (2015) Functions of melatonin in plants: a review. J Pineal Res 59(2):133-150

Arnon DI (1949) Copper enzymes in isolated chloroplasts. Polyphenoloxidases in Beta vulgaris. Plant Physiol 24(1):1-15

Ashraf U, Kanu AS, Mo ZW, Hussain S, Anjum SA, Khan I, Abbas RN, Tang XR (2015) Lead toxicity in rice: effects, mechanisms, and mitigation strategies-a mini review. Environ Sci Pollut Res 22(23): 18318-18332

Avramova V, AbdElgawad H, Zhang ZF, Fotschki B, Casadevall R, Vergauwen L, Knapen D, Taleisnik E, Guisez Y, Asard H, Beemster GTS (2015) Drought induces distinct growth response, protection, and recovery mechanisms in the maize leaf growth zone. Plant Physiol 169(2):1382-1396

Chaves MM, Oliveira MM (2004) Mechanisms underlying plant resilience to water deficits: prospects for water-saving agriculture. J Exp Bot 55(407):2365-2384

Cornic G (2000) Drought stress inhibits photosynthesis by decreasing stomatal aperture - not by affecting ATP synthesis. Trends Plant Sci 5(5):187-188

Croft H, Chen JM, Luo XZ, Bartlett P, Chen B, Staebler RM (2017) Leaf chlorophyll content as a proxy for leaf photosynthetic capacity. Glob Chang Biol 23(9):3513-3524

Emmerich WE, Hardegree SP (1990) Polyethylene glycol solution contact effects on seed germination. Agron J 82(6):1103-1107

Erland LAE, Yasunaga A, Li ITS, Murch SJ, Saxena PK (2018) Direct visualization of location and uptake of applied melatonin and serotonin in living tissues and their redistribution in plants in response to thermal stress. J Pineal Res 66(1):e12527

Faccioli G, Rosner A, Forni M (1995) Use of the polymerase chain reaction to clone the potato leafroll virus coat protein gene directly from the total RNA of infected plants. Potato Res 38(2):211-218

Finkelstein RR, Gampala SS, Rock CD (2002) Abscisic acid signaling in seeds and seedlings. Plant Cell 14:S15-45

Fujita Y, Fujita AM, Satoh CR, Maruyama CK, Parvez AMM, Seki AM (2005) AREB1 is a transcription activator of novel ABREDependent ABA signaling that enhances drought stress tolerance in Arabidopsis. Plant Cell 17(12):3470

Gaxiola RA, Li J, Undurraga S, Dang LM, Allen GJ, Alper SL, Fink GR (2001) Drought- and salt-tolerant plants result from overexpression of the AVP1 H+-pump. PNAS 98(20):11444-11449

Gray J (2005) guard cells: transcription factors regulate stomatal movements. Curr Biol 15(15):R593-R595

Griffiths H, Parry MAJ (2002) Plant responses to water stress. Ann Bot 89(7):801-802

Gururani MA, Venkatesh J, Tran LSP (2015) Regulation of Photosynthesis during Abiotic Stress-Induced Photoinhibition. Mol plant 89:1304-1320

Hamurcu M, Sekmen AH, Turkan I, Gezgin S, Demiral T, Bell RW (2013) Induced anti-oxidant activity in soybean alleviates oxidative stress under moderate boron toxicity. Plant Growth Regul 70(3):217-226

Hu XL, Wang W, Li CQ, Zhang JH, Lin F, Zhang AY, Jiang MY (2008) Cross-talk between $\mathrm{Ca}^{2+} / \mathrm{CaM}$ and $\mathrm{H}_{2} \mathrm{O}_{2}$ in abscisic acid-induced antioxidant defense in leaves of maize plants exposed to water stress. Plant Growth Regul 55:183-198
Ippolito MP, Fasciano C, Daquino L, Tommasi F (2011) Responses of antioxidant systems to lanthanum nitrate treatments in tomato plants during drought stress. Plant Biosyst 145(1):248-252

Janas KM, Posmyk MM (2013) Melatonin, an underestimated natural substance with great potential for agricultural application. Acta Physiol Plant 35(12):3285-3292

Kakkar P, Das B, Viswanathan PN (1984) A modified spectrophotometric assay of superoxide dismutase. Indian J Biochem Biophys 21(2):130-132

Kang GZ, Li GZ, Liu GQ, Xu W, Peng XQ, Wang CY, Zhu YJ, Guo TC (2013) Exogenous salicylic acid enhances wheat drought tolerance by influence on the expression of genes related to ascorbateglutathione cycle. Biol Plant 57(4):718-724

Kim S, Kim TH (2020) Alternative splicing for improving abiotic stress tolerance and agronomic traits in crop plants. J Plant Biol 63:409-420

Kushiro T, Okamoto M, Nakabayashi K, Yamagishi K, Kitamura S, Asami T, Hirai N, Koshiba T, Kamiya Y, Nambara E (2004) The Arabidopsis cytochrome P450 CYP707A encodes ABA 8'-hydroxylases: key enzymes in ABA catabolism. EMBO J 23(7):1647-1656

Lerner AB, Case JD, Takahashi Y, Lee TH, Mori W (1958) Isolation of melatonin, the pineal gland factor that lightens melanocytes. J Am Chem Soc 80(10):2587-2587

Li Y, Zhao HX, Duan BL, Korpelainen H, Li CY (2011) Effect of drought and ABA on growth, photosynthesis and antioxidant system of Cotinus coggygria seedlings under two different light conditions. Environ Exp Bot 71(1):107-113

Li C, Tan DX, Liang D, Chang C, Jia DF, Ma FW (2015) Melatonin mediates the regulation of $\mathrm{ABA}$ metabolism, free-radical scavenging, and stomatal behaviour in two Malus species under drought stress. J Exp Bot 66(3):669-680

Liu ZJ, Zhang XL, Bai JG, Suo BX, Xu PL, Wang L (2009) Exogenous paraquat changes antioxidant enzyme activities and lipid peroxidation in drought-stressed cucumber leaves. Sci Hortic 121(2):138-143

Liu YG, Ye NH, Liu R, Chen MX, Zhang JH (2010) H2O2 mediates the regulation of ABA catabolism and GA biosynthesis in Arabidopsis seed dormancy and germination. J Exp Bot 61(11):2979-2990

Liu N, Jin ZY, Wang SS, Gong B, Wen D, Wang XF, Wei M, Shi QH (2015) Sodic alkaline stress mitigation with exogenous melatonin involves reactive oxygen metabolism and ion homeostasis in tomato. Sci Hortic 181:18-25

Livak KJ, Schmittgen TD (2001) Analysis of relative gene expression data using real-time quantitative PCR and the 2(-Delta Delta C(T)) Method. Methods 25(4):402-408

Lobell DB, Roberts MJ, Schlenker W, Braun N, Little BB, Rejesus RM, Hammer GL (2014) Greater Sensitivity to Drought Accompanies Maize Yield Increase in the U. S. Midwest. Ence 344(6183):516-519

Ma FW, Cheng LL (2003) The sun-exposed peel of apple fruit has higher xanthophyll cycle-dependent thermal dissipation and antioxidants of the ascorbate-glutathione pathway than the shaded peel. Plant Sci 165(4):819-827

Ma XQ, Zhang J, Burgess P, Rossi S, Huang BR (2018) Interactive effects of melatonin and cytokinin on alleviating drought-induced leaf senescence in creeping bentgrass (Agrostis stolonifera). Environ Exp Bot 145:1-11

Meher SP, Ashok Reddy K, Manohar Rao D (2018) Effect of PEG6000 imposed drought stress on RNA content, relative water content (RWC), and chlorophyll content in peanut leaves and roots. Saudi J Biol Sci 25(2):285-289

Meng JF, Xu TF, Wang ZZ, Fang YL, Xi ZM, Zhang ZW (2014) The ameliorative effects of exogenous melatonin on grape cuttings 
under water-deficient stress: antioxidant metabolites, leaf anatomy, and chloroplast morphology. J Pineal Res 57(2):200-212

Nambara E, Marionpoll A (2005) Abscisic acid biosynthesis and catabolism. Annu Rev Plant Biol 56(1):165-185

Pandey V, Dixit V, Shyam R (2009) Chromium effect on ROS generation and detoxification in pea (Pisum sativum) leaf chloroplasts. Protoplasma 236(1-4):85-95

Paredes SD, Korkmaz A, Manchester LC, Tan DX, Reiter RJ (2009) Phytomelatonin: a review. J Exp Bot 60(1):57-69

Park WJ (2011) Melatonin as an endogenous plant regulatory signal: debates and perspectives. J Plant Biol 54(3):143-149

Peterson KM, Rychel AL, Torii KU (2010) Out of the mouths of plants: the molecular basis of the evolution and diversity of stomatal development. Plant Cell 22(2):296-306

Qin X, Zeevaart JA (1999) The 9-cis-epoxycarotenoid cleavage reaction is the key regulatory step of abscisic acid biosynthesis in water-stressed bean. PNAS 96(26):15354-15361

Reddy AR, Chaitanya KV, Vivekanandan M (2004) Drought-induced responses of photosynthesis and antioxidant metabolism in higher plants. J Plant Physiol 161(11):1189-1202

Saito S, Hirai N, Matsumoto C, Ohigashi H, Ohta D, Sakata K, Mizutani M (2004) Arabidopsis CYP707As Encode (+)-abscisic acid 8 '-hydroxylase, a key enzyme in the oxidative catabolism of abscisic acid. Plant Physiol 134(4):1439-1449

Sanchita SR, Mishra A, Dhawan SS, Shirke PA, Gupta MM, Sharma A (2015) Physiological performance, secondary metabolite and expression profiling of genes associated with drought tolerance in Withania somnifera. Protoplasma 252(6):1439-1450

Schneider K, Schlegel HG (1981) Production of superoxide radicals by soluble hydrogenase from Alcaligenes eutrophus H16. Biochem J 193(1):99-107

Schroeder JI, Allen GJ, Hugouvieux V, Kwak JM, Waner D (2001) Guard cell signal transduction. Annu Rev Plant Physiol Plant Mol Biol 52(4):627

Shapiguzov A, Vainonen JP, Wrzaczek M, Kangasjärvi J (2012) ROStalk-how the apoplast, the chloroplast, and the nucleus get the message through. Front Plant Sci 3:292

Tan DX, Manchester LC, Terron MP, Flores LJ, Reiter RJ (2007) One molecule, many derivatives: a never-ending interaction of melatonin with reactive oxygen and nitrogen species? J Pineal Res 42(1):28-42

Tan DX, Hardeland R, Manchester LC, Korkmaz A, Ma S, Rosalescorral S, Reiter RJ (2012) Functional roles of melatonin in plants, and perspectives in nutritional and agricultural science. J Exp Bot 63(2):577-597

Thordal-Christensen H, Zhang ZG, Wei YD, Collinge DB (1997) Subcellular localization of $\mathrm{H}_{2} \mathrm{O}_{2}$ in plants. $\mathrm{H}_{2} \mathrm{O}_{2}$ accumulation in papillae and hypersensitive response during the barley-powdery mildew interaction. Plant J 11(6):1187-1194

Timothy J, Brodribb SAM (2013) Abscisic acid mediates a divergence in the drought response of two conifers. Plant Physiol 162(3):1370-1377

Tiryaki I, Keles H (2012) Reversal of the inhibitory effect of light and high temperature on germination of Phacelia tanacetifolia seeds by melatonin. J Pineal Res 52(3):332-339
Upadhyaya A, Sankhla D, Davis TD, Sankhla N, Smith BN (1985) Effect of paclobutrazol on the activities of some enzymes of activated oxygen metabolism and lipid peroxidation in senescing soybean leaves. J Plant Physiol 121(5):453-461

Wang P, Sun X, Li C, Wei ZW, Liang D, Ma FW (2013) Long-term exogenous application of melatonin delays drought-induced leaf senescence in apple. J Pineal Res 54(3):292-302

Wang P, Sun X, Xie YP, Li MJ, Chen W, Zhang S, Liang D, Ma FW (2014) Melatonin regulates proteomic changes during leaf senescence in Malus hupehensis. J Pineal Res 57(3):291-307

Wang JF, Chen JJ, Sharma A, Tao SC, Zheng BS, Landi M, Yuan HW, Yan DL (2019a) Melatonin stimulates activities and expression level of antioxidant enzymes and preserves functionality of photosynthetic apparatus in hickory plants (Carya cathayensis Sarg.) under PEG-promoted drought. Agronomy 9(11):702

Wang ZL, Zhang CS, Ding F (2019b) Exogenous melatonin delays methyl jasmonate-triggered senescence in tomato leaves. Agronomy 9:795

Wei W, Li QT, Chu YN, Reiter RJ, Yu XM, Zhu DH, Zhang WK, Ma B, Lin Q, Zhang J (2015) Melatonin enhances plant growth and abiotic stress tolerance in soybean plants. J Exp Bot 66(3):695-707

Ye J, Wang SW, Deng XP, Yin LN, Xiong BL, Wang XY (2016) Melatonin increased maize (Zea mays L.) seedling drought tolerance by alleviating drought-induced photosynthetic inhibition and oxidative damage. Acta Physiol Plant 38(2):48

Ye J, Yang WJ, Li YL, Shiwen W, Yin LN, Deng XP (2020) Seed presoaking with melatonin improves wheat yield by delaying leaf senescence and promoting root development. Agronomy 10:84

Yordanov I, Velikova V, Tsonev T (2000) Plant responses to drought, acclimation, and stress tolerance. Photosynthetica 38(2):171-186

Zhang JH, Jia WS, Yang JC, Ismail AM (2006) Role of ABA in integrating plant responses to drought and salt stresses. Field Crops Res 97(1):111-119

Zhang N, Zhao B, Zhang HJ, Weeda S, Yang C, Yang ZC, Ren SX, Guo YD (2013) Melatonin promotes water-stress tolerance, lateral root formation, and seed germination in cucumber (Cucumis sativus L.). J. Pineal Res 54(1):15-23

Zhang N, Sun QQ, Zhang HJ, Gao YY, Weeda S, Ren SX, Guo YD (2015) Roles of melatonin in abiotic stress resistance in plants. J Exp Bot 66(3):647-656

Zheng XD, Zhou JZ, Tan DX, Wang N, Wang L, Shan DQ, Kong J (2017) Melatonin improves waterlogging tolerance of Malus baccata (Linn.) Borkh. seedlings by maintaining aerobic respiration, photosynthesis and ROS migration. Front Plant Sci 8:483-483

Zhou J, Wang J, Li X, Xia XJ, Zhou YH, Shi K, Chen ZX, Yu JQ (2014) $\mathrm{H}_{2} \mathrm{O}_{2}$ mediates the crosstalk of brassinosteroid and abscisic acid in tomato responses to heat and oxidative stresses. J Exp Bot 65(15):4371-4383

Ziyomo C, Bernardo RN (2013) Drought tolerance in maize: indirect selection through secondary traits versus genomewide selection. Crop Sci 53(4):1269-1275

Zou DS, Kahnt G (2008) Effect of air humidity on photosynthesis and transpiration of soybean leaves. J Agron Crop Sci 161(3):190-194 